\title{
Nano-immunotherapeutics: targeting approach as strategic regulation at tumor microenvironment for cancer treatment
}

\author{
Priyanka Singh, Monika Yadav, Karishma Niveria, Anita Kamra Verma*i] \\ Nano-Biotech Lab, Kirori Mal College, University of Delhi, Delhi 110007, India \\ *Correspondence: Anita Kamra Verma, Nano-Biotech Lab, Kirori Mal College, University of Delhi, Delhi 110007, India. \\ akamra23@hotmail.com; akverma@kmc.du.ac.in \\ Academic Editor: Haijun Yu, Chinese Academy of Sciences, China
}

Received: August 2, 2021 Accepted: November 10, 2021 Published: February 16, 2022

Cite this article: Singh P, Yadav M, Niveria K, Verma AK. Nano-immunotherapeutics: targeting approach as strategic regulation at TME for cancer treatment. Explor Med. 2022;3:22-42. https://doi.org/10.37349/emed.2022.00072

\begin{abstract}
Cancer is the leading cause of mortality worldwide, which necessitates our consideration related to novel treatment approach. Tumor cells at the tumor microenvironment (TME), regulate a plethora of key mechanistic signaling pathways that obstruct antitumor immune responses by immune suppression, immune resistance or acquired immune tolerance. The present therapeutic regimes are provided independently or in combination, or as immunotherapies for cancer immune targeting. Immunotherapy has altered the arena of oncology and patient care. By using the host immune system, the immunostimulatory molecules can exert a robust, personalized response against the patient's own tumors. Alternatively, tumors may exploit these strategies to escape immune recognition, and accordingly, such mechanisms represent chances for immunotherapy intervention. Nonetheless, despite promising outcomes from immunotherapies in recurrent and metastatic cancers, immune-therapeutics in clinics have been limited owing to unpredictability in the produced immune response and reported instances of immune-related adverse effects. The unrealized potential of immunotherapies in cancer management maybe due to the obstacles such as heterogeneous nature, multiple targets, patients' immune response, specificity for cancer or variability in response generation in toxicity levels, delivery and cost related to therapeutics etc. Further revolutionary trends related to immunotherapies are noticeable with slower progress for cancer management. Recent advances in nanomedicine strategize to ameliorate the lacuna of immunotherapy as it relies on the inherent biophysical characteristics of nanocarriers: size, shape, surface charge and multifunctionality and exploiting them as first line therapy for delivery of biomolecules, single checkpoint inhibitors and for imaging of TME. Therefore, nano-assisted immunotherapies can boost the immunotherapeutic approach, overcoming factors that are with imminent potential risks related to it, thereby significantly improving the survival rate associated with it in cancer patients. Nanotechnology is anticipated to overcome the confines of existing cancer immunotherapy and to successfully combine various cancer treatment modes.
\end{abstract}

\section{Keywords}

Nano-assisted immunotherapies, tumor microenvironment, nanomedicine 


\section{Introduction}

Global cancer statistics for last year sourced from International Agency for Research on Cancer (IARC) Global Cancer Observatory (GLOBOCAN), represents breast, lung and prostate cancers as high-ranking cancer cases enlisted as major diagnosed cancers while lung, liver and stomach cancers related mortality was high, which reflects economic burden allied to suffering in cancer patients [1].

Tumor microenvironment (TME) is an ecological niche with a heterogeneous nature, manifested with unusual diverse population of cells, cancer and associated cell population, immune cell population etc. with specific characteristics. Presence of adverse acidic condition, hypoxia, elevated reactive oxygen species (ROS) etc. influences the survival and persistence of protumor and antitumor biomolecules, by either supporting or targeting cancer, with course of time [2,3]. Tumor cells at the TME, regulate a plethora of key mechanistic signaling pathways that intend to obstruct antitumor immune responses by immune suppression, immune resistance or through acquired immune tolerance. Events that drive the vicious circle of tumor survival involve a continual input in the form of surface marker expressions such as tumor associated antigens (TAAs), major histocompatibility complex (MHC), programmed death-ligand 1 (PD-L1), tumor necrosis factor (TNF)-related apoptosis-inducing ligand (TRAIL) etc., a sustained secretary pool of chemical mediators such as chemokines, cytokines that include transforming growth factor- $\beta$ (TGF- $\beta$ ), interleukin-10 (IL-10), growth factors like vascular endothelial growth factor (VEGF), participating in the recruitment of protumor cells, inhibition of antitumor survivor at TME in a direct or indirect way, under regulatory guidance from cancer immune signaling pathways [3]. Advances over the past few decades have shown promising results for cancer management in form of emerging chemotherapies, co-delivery of immunomodulators with radiotherapies, combinatorial therapies etc. Recent progress has further highlighted cancer immunotherapies as an advanced treatment approach with effectual response relying on specificity of the targeted treatment and molecular uniqueness being specific for each cancer. It is considered far better than conventional approach where cells with elevated multiplicity and amplification were targeted through numerous anticancer drugs and antioxidants performing tumor regressive action that is achieved by modulating immune response within TME. Immunotherapy emerged as a branch of oncotherapy that modulates the host immune response against cancer. Originating from recombinant cytokine therapy, immunotherapy entails several therapeutic approaches including cancer vaccines, monoclonal antibody $(\mathrm{mAb})$ along with cellular, gene therapies, adaptive cell transfer therapies and oncolytic virus therapies [4].

Nonetheless, despite promising outcomes from immunotherapies in recurrent and metastatic cancers, immune therapy in clinics has been limited owing to unpredictability in the produced immune responses and reported instances of immune-related adverse effects. The drawbacks are due to selective favorable outcomes for specific cancers in few subsets of patients, acquired resistance to particular immunotherapy and toxicity associated with immune-combinational therapies to overcome resistance. Additionally, heterogonous targets and target identification with selective biomarkers are specific for cancer type and subtype. This unpredictability can be overcome by using nanoparticles that play a vital role owing to their unique properties for enhanced and effective delivery of cancer antigens and adjuvants to specific sites especially delivery of immunomodulators at TME for prolonged immune responses. Further standardized design for clinical trials along with its evaluation and expensive cost allied with cancer immunotherapies are all major concerns $[5,6]$.

Evolutionary success relies on the immune systems' perception and response to nano- and micro-particulates (e.g., bacteria and viruses) that are recognized as foreign pathogens. Engineering nanoparticles with precise size, composition, shape and/or surface functionalized properties can elicit an appropriate immune response by using nano-assisted immunotherapies. Therefore, development and implementation of nano-assisted technologies has enormous potential for cancer management [7]. Further, exploring nano-assisted immunotherapies can congregate together to provide distinctive innovations for cancer management $[8,9]$. This article reviews issues related to immune 
crosstalk at the TME and the mechanistic signaling pathways involved in it for overcoming obstacles in form of nano-assisted immunotherapies.

\section{TME}

Oncogenic nature of cancer, cancer-associated cells and immune cells at TME

The process of transformation of cells acquiring cancerous nature is favored with specific conditions at TME including acidic $\mathrm{pH}$, hypoxia and elevated ROS. Its impact on diverse cell population such as cancer/tumor cells, tumor specific adipocytes (TSAs, energy supply), tumor specific fibroblasts (TSFs), tumor specific endothelial cells (TSECs, nutritional supply), tumor specific pericytes (TSPs, remodeling at TME) enables them to participate in tumorigenesis [10]. TSAs act as tumor supporter through the recruitment and differentiation of immune cells with protumor fate under the influence of mediator molecules like [IL-8/VEGF/TGF- $\beta$ / TNF- $\alpha$ /hepatocyte growth factor (HGF)/plasminogen activator inhibitor-1/monocyte chemoattractant protein-1 (MCP1)] [11]. Similarly, TSECs were associated with tumor evasion due to dysfunctional surface expression of TRAIL/Fas ligand (FasL)/PD-L1/PD-L2, which might also have deleterious consequences relating to antitumor responses such as reduced infiltrating immune cells within TME $[10,12,13]$. TSPs in synchronization with TSECs promote PD-L1 expressions that will correspond to its protumor nature. TSFs are known to have reciprocal relation with cancer cells, various secretions from cancer cells like growth factors: platelet derived growth factor, fibroblast growth factor (PDGF, FGF), IL-1, cancer vesicles or exosomes interact with TSFs and introduce differential changes in it. TSFs further allow prolonged survival of tumor cells along with oncogenic invasion via specific matrix metalloproteinase [MMPs (MMP-2/MMP-9)], oncogenic proliferation [stromal cell-derived factor-1 (SDF-1)/FGF/IL-6/TGF- $\beta$ /osteopontin] and oncogenic angiogenesis (VEGF/FGF2/FGF7) etc. [10,14].

Resident immune cells at TME include protumor cohort and antitumor cohort, both performing distinctive functional roles $[15,16]$. Resident tumor associated neutrophils (TANs) at TME are represented as antitumor neutrophils (TAN1) and protumor neutrophils (TAN2). Presence of TAN1 type neutrophils instruct antitumor immune cells such as cytotoxic T lymphocytes cells ( $\mathrm{T}$ cells) to eliminate tumor through cell death initiation and ROS generation eventually leading to tumor regression. Also, TAN1 via antibody dependent cellular cytotoxicity (ADCC) initiate their accumulation at tumor site for antitumor response. TAN2 type neutrophils are involved in immunosuppression and they also restrain functional response of antitumor $\mathrm{CD}^{+} \mathrm{T}$ cells $[16,17]$. Resident tumor associated macrophages (TAMs) at TME are classified as tumor suppressive (TAM1) and tumor supportive (TAM2) macrophages. They undergo differentiation to acquire a regulatory function by various pro/anti-inflammatory cytokines, chemokines, growth factors, ROS, hypoxia etc. Immunosuppression is regulated by targeting programmed cell death 1 (PD-1)/PD-L1 immune checkpoint signaling pathway that can be critical for tumor regression $[16,18,19]$. Similarly, active myeloid derived suppressor cells (MDSCs) amplify the immunosuppressive expression of TAMs with the release of arginase (ARG1)/inducible nitric oxide synthase (iNOS)/ROS, like protumor factors. They also overexpress indoleamine 2, 3-dioxygenase (IDO) thereby targeting antitumor potential of active natural killer cells (NK cells), T cells, B lymphocytes cells (B cells). MDSCs stimulate CD4 ${ }^{+} \mathrm{T}$ cell tolerance in an MHC dependent manner. Correlation in MDSCs and T regulatory cells (Tregs) is such that MDSCs stimulate Tregs for their functional response and this encourages Tregs to enhance the differentiation of MDSCs by releasing TGF- $\beta[16,20]$. Tregs are cancer promoting in direct and indirect ways with the release of various chemokines [C-C motif chemokine ligands (CCLs)] and cytokines (TGF- $\beta /$ IL-10/IL-35). Indirectly, they induce tolerance in dendritic cells (DCs) by removing peptide MHC complexes, therefore blocking their antigen presentation and processing to T cells and directly by increasing levels of IL-10, TGF- $\beta$ and CD25 where TGF- $\beta$ further inhibits functional response for NK cells. Further, Tregs promote various inhibitory signal mediators such as PD-1, lymphocyte-activation gene 3 ( $L A G-3)$, and transmembrane immunoglobulin and mucin domain 3 (TIM-3). These mediators are further involved in lysis of antitumor expression of $\mathrm{T}$ cells along with other antigen presenting cells (APCs) at TME [16, 21]. 
The inappropriate DCs stimulation at TME encourages tolerogenic DCs (tDCs) to represent the tumor antigen, which will further ensure tolerant response generation at $\mathrm{T}$ cells $[16,22,23]$. Recruitment of tumor infiltrating lymphocytes (TILs) at TME confronts tumor growth with substantial support from other antitumor immune cells $\mathrm{CD} 3^{+} / \mathrm{CD}^{+} / \mathrm{CD}^{+}$TILs along with NK cells, but multiple targeting of antitumor immune cells blocks the cytotoxic/chemokine response from them, responsible for immunosuppressive conditions at TME. Cytotoxic actions of CD8 ${ }^{+}$TILs against growing tumor are mediated through cell death pathways involving dysregulated receptor ligand interaction (death receptors, FasL and TRAIL) or by release of perforin and granzyme B. Tumor cells show shielded response against killer cytotoxic T lymphocytes (CTLs) by downregulated expression of antigen recognition, its processing and presenting ability. CTLs also undergo regulatory changes where they represent upregulated expression of checkpoint receptors like PD-1, cytotoxic T lymphocyte associated antigen 4 (CTLA-4), LAG-3, and TIM-3, making them more vulnerable to inhibitory signals responsible for CTLs undergoing anergy. Role of T helper type 1 (Th1) cells is to assist CTLs killer response by releasing IL- 2 or interferon- $\gamma$ (IFN- $\gamma$ ), but $\mathrm{CD} 4^{+} \mathrm{Th} 2$ cells might encourage tumor growth by obstructing Th1 mediated antitumor immunity $[16,23]$. Similarly, NK cells are also killer immune cells and tumor cells manage to flee from NK cells surveillance at TME with the help of mediators such as TGF- $\beta$, IFN- $\gamma$, signal transducer and activator of transcription 3 (STAT3) and hypoxia like factors by downregulating NK cells specific activating expression of CD16, natural killer group 2D (NKG2D), and DNAX accessory molecule-1 (DNAM-1) [24] (Table 1).

Table 1. Tabular representation of various oncogenic cells at TME

\begin{tabular}{|c|c|c|c|c|}
\hline $\begin{array}{l}\text { Tumor } \\
\text { microenvironment }\end{array}$ & $\begin{array}{l}\text { Different } \\
\text { cells at TME }\end{array}$ & Nature & Inference & Reference \\
\hline \multirow[t]{5}{*}{$\begin{array}{l}\text { Cancer and cancer } \\
\text { associated cells at TME }\end{array}$} & Cancer cells & Protumor & $\begin{array}{l}\text { Cancer cells contribute to metabolic reprogramming of } \\
\text { other cancer associated cells and immune cells thus } \\
\text { supporting tumorigenesis at TME. }\end{array}$ & [10] \\
\hline & TSAs & Protumor & $\begin{array}{l}\text { TSAs meets the energy demand presented before them by } \\
\text { cancer cells for pivotal oncogenic regulation at TME. This } \\
\text { is marked with amplified pro-inflammatory expression of } \\
\text { cytokines (IL-1 } \beta, \text { IL-6, IL-10), MMP-11 etc. }\end{array}$ & [11] \\
\hline & TSECS & Protumor & $\begin{array}{l}\text { Tumor specific endothelial cells (TSECs) has their decisive } \\
\text { role in tumor metastasis, where angiogenesis, vascular } \\
\text { permeability, transport regulation etc. redirect immune cells } \\
\text { and other cells at TME. }\end{array}$ & {$[12,13]$} \\
\hline & TSPs & Protumor & $\begin{array}{l}\text { TSPs has crucial role in angiogenic regulation (blood } \\
\text { vasculature, extracellular matrix remodeling) at TME. }\end{array}$ & [10] \\
\hline & TSFs & Protumor & $\begin{array}{l}\text { Role of TSFs in oncogenic invasion, proliferation and } \\
\text { angiogenesis. Its crosstalk with resident immune cells } \\
\text { reveals that secretion (TGF- } \beta \text {, IL-10, M-CSF) from TSFs } \\
\text { target antitumor immune cells either by restraining their } \\
\text { response generation or by dysfunctional response initiation } \\
\text { (T cells, NK cells, DCs etc.), while differentiating other } \\
\text { immune cells (TAM2, TAN2, Treg etc.) to acquire protumor } \\
\text { phenotype with tumor supporting action. }\end{array}$ & [14] \\
\hline \multirow[t]{5}{*}{ Immune cells at TME } & TANs & TAN2 & \multirow{2}{*}{$\begin{array}{l}\text { Presence of TAN2 type neutrophils recruits other protumor } \\
\text { immune cells performing tumorigenic activities such as } \\
\text { angiogenesis and metastasis by release of VEGF, ROS, } \\
\text { inflammatory cytokines (TNF- } \alpha, \mathrm{IL}-1 \beta, \mathrm{IL}-6, \mathrm{IL}-12 \text { ) etc. }\end{array}$} & \multirow[t]{2}{*}[17]{} \\
\hline & & TAN1 & & \\
\hline & \multirow[t]{2}{*}{ TAMs } & TAM1 & \multirow[b]{2}{*}{$\begin{array}{l}\text { Crosstalk with other immune cells (MDSCs, Treg, Th2, } \\
\text { CD8 }{ }^{+} \text {cells, NK cells etc.) cancer cells and cancer } \\
\text { associated cells contributes to oncogenic regulations } \\
\text { leaded by release of VEGF, cytokines (IL-1, TNF- } \alpha \text { ), } \\
\text { extracellular matrix (ECM) degrading molecules [urokinase- } \\
\text { type plasminogen activator (UPA), MMP7, MMP9 etc.] } \\
\text { further additional factors such as TGF- } \beta \text {, HGF/basic } \\
\text { fibroblast growth factor (bFGF)/prostaglandin E2 (PGE2) } \\
\text { etc. are also involved in immune suppressive action. }\end{array}$} & \multirow[t]{2}{*}[18,19]{} \\
\hline & & TAM2 & & \\
\hline & MDSCs & Protumor & $\begin{array}{l}\text { MDSCs interact with both residing tumor and immune cells } \\
\text { and initiate a signaling event where it amplifies immune } \\
\text { suppressive expression. }\end{array}$ & [20] \\
\hline
\end{tabular}


Table 1. Tabular representation of various oncogenic cells at TME (continued)

\begin{tabular}{|c|c|c|c|c|}
\hline $\begin{array}{l}\text { Tumor } \\
\text { microenvironment }\end{array}$ & $\begin{array}{l}\text { Different } \\
\text { cells at TME }\end{array}$ & Nature & Inference & Reference \\
\hline & Tregs & Protumor & $\begin{array}{l}\text { It targets functional activity of T cells, NK cells in indirect } \\
\text { and direct way. }\end{array}$ & [21] \\
\hline & \multirow[t]{2}{*}{ DCs } & $\begin{array}{l}\text { Protumor } \\
\text { tDCs }\end{array}$ & \multirow{2}{*}{$\begin{array}{l}\text { tDCs represent inferior level of costimulatory molecules } \\
\text { (CD80, CD86) expressed on their surface, vice-verse } \\
\text { reported for inhibitory molecules (PD-L1/CTLA-4 etc.) } \\
\text { responsible for immune suppressive action. The stimuli } \\
\text { input for tDCs functioning comes from VEGF/cytokines } \\
\text { (TGF- } \beta \text {, IL-10), and IL-10 secreting Treg cells etc. they } \\
\text { liberate a range of immunomodulatory factors (TRAIL/ } \\
\text { PD-L1/DC-SIGN galactin-1) and immunosuppressive } \\
\text { molecules (TGF- } \beta / \text { /L-10/IL-27/NO/IDO). }\end{array}$} & \multirow[t]{2}{*}[22,23]{} \\
\hline & & $\begin{array}{l}\text { Antitumor } \\
\text { DCs }\end{array}$ & & \\
\hline & CTLs & Antitumor & $\begin{array}{l}\text { Obstacle at Th1 mediated antitumor immunity promote } \\
\text { protumor immune response. }\end{array}$ & [23] \\
\hline & NK cells & Antitumor & $\begin{array}{l}\text { Release of TGF- } \beta \text {, IFN- } \gamma \text {, STAT3, hypoxia like factors } \\
\text { downregulates NK cells active expression. }\end{array}$ & [24] \\
\hline
\end{tabular}

\section{Molecular signaling pathways and its regulation at TME}

Principle management of cancer related adversity necessitates identification of pathways that are involved in suppressive or resistant immune response at TME $[25,26]$. Various cancer studies have reported the involvement of $\beta$-catenin in immune suppressive activities at TME [27]. In vitro and in vivo studies in melanoma mice models, in an induced or effector phase response reveal the involvement of CTLs and DCs like immune cells for effective antitumor immune response. But overexpressed levels of $\beta$-catenin obstruct the production of IFN- $\gamma$ from CTLs. This indicates that partial regulation from IL-10 introduces more immune suppression and resistance in residing immune cells at TME [27]. Melanoma derived Wnt5a also promote IDO stimulated immunotolerance in DCs [28]. Constitutively active STAT3 and dominant negative STAT3 signaling represents elevated expression of proinflammatory chemokines such as CCL5 and C-X-C motif chemokine ligand 10 (CXCL10), indicating their involvement in immune-resistance at TME [29]. Role of phosphoinositide-3-kinase/phosphatase and tensin homolog/protein kinase B/mammalian target of rapamycin (PI3K/PTEN/AKT/mTOR) signaling pathway disturbs antitumor immune regulation by downmodulating the functional immune cells activity. Studies from triple negative breast cancer (TNBC) [30], human lung squamous cell carcinoma and gliomas [31] showed inverse relation between active tumor suppressor (PTEN) and PD-L1 expression. Their association with PI3K pathway in infiltrating T cell at TME is well described in TNBC [30]. In sarcoma [32] and prostate cancer [33], recruitment of MDSCs, TAMs, and TANs at tumor site are also guided by PI3K expression. These findings indicate that activation of the PI3K/AKT signaling pathway represents a new mechanism of immune escape that has important implications for the development of a novel cancer immunotherapeutic strategy against immune resistant tumors. $p 53$ has a tumor suppressive role, but its mutant variant is known to be associated with oncogenic events at TME therefore, targeting such signaling pathway can be an immunological strategy for modulating immune response at TME $[34,35]$. $p 53$ related targeting of melanoma both in vitro and in vivo reveals that, antitumor suppression was reinstated with subsequent administration of nutlin-3a ( $p 53$ activator). The process involves two different ways of targeting: $p 53$-dependent restoration of immunostimulatory response at TME and p53-dependent tumor targeting and augmented antitumor immunity. Collectively, these findings represent steady-state role of p53 signaling pathway in cancer immune regulations [36]. Nuclear factor kappa-light-chain enhancer of activated B cells (NF- $\kappa$ B) signaling pathway with constitutive expression of NF- $\kappa B$ also regulates oncogenic events and emphasizes significant role of intrinsic NF- $\mathrm{B}$ expression in immune response regulation at TME [37]. Involvement of (sarcoma virus, rat sarcoma virus) RAS/rapidly accelerated fibrosarcoma (RAF)/mitogen activated protein kinase (MAPK) signaling pathway initiates signaling cascade that activates genes imperative for oncogenesis and it further upregulates the expression of PD-1 by stimulating extracellular signal-regulated kinase (p-ERK) signaling [38, 39]. Its role in recruitment of various immunosuppressive cells like Tregs, TAMs, TANs, and MDSCs, at tumor 
specific site is depicted in non-small cell lung cancer (NSCLC) along with other cancer studies. These studies reveal the involvement of serine/tyrosine/threonine kinase-extracellular signal-regulated kinase-activator protein 1 (MEK-ERK-AP1) pathway with MYC co-activation [40-42]. Literature survey regarding lung adenocarcinomas reveals that targeting IFN-I/stimulator of interferon gene (STING) signaling pathway at glycogen branching enzyme (GBE1), inhibits the PD-L1 expression, and promotes release of chemokines (CCL5 and CXCL10) for recruitment of antitumor CD8 ${ }^{+} \mathrm{T}$ lymphocytes at TME. Kirsten rat sarcoma (KRAS)-mutation along with co-activated expression of MYC is known for introducing more deleterious immune suppressive response by excluding the recruitment of many antitumor adaptive immune cells such as B cells, T cells, and NK cells [43], through amplified expression of IL-23, chemokine (CCL9). The epidermal growth factor receptor (EGFR) was regulated or involved with other signaling pathways in different cancers. NSCLC, it is regulated through IL-6/JAK/STAT3 [44], in head and neck cancers JAK2/STAT1 pathway is involved [45], and in esophageal squamous cell carcinoma EGFR/PI3K/AKT [46], EGFR/RAS/RAF/ERK, and early growth response/phospholipase C-gamma (EGR/PLC- $\gamma$ ) signaling pathways are involved. The EGFR signaling pathways are responsible for regulating PD-L1 expression and immune suppression too [47]. Further involvement of Hippo signaling pathway is also evident and targeting it at large tumor suppressor kinase 1/2 (LATS1/2) can be promising for immunotherapeutic efficacy against cancer [48, 49]. The studies from thyroid carcinoma have showed the direct association between ID01 expression and the oncogenic stimulation of rearranged during transfection (RET) and therefore, illustrate the involved signal transduction pathway [50,51]. While mutant isocitrate dehydrogenase in glioma is associated with possible mechanism of immune suppression, as NK cells acquire resistance via epigenetic regulation [52]. The cancer immune signaling pathways will enable researchers and clinicians to come up with new therapeutic strategies for effective targeting of cancer immune regulation with advancement in existing immunotherapies (Table 2).

Table 2. Studies from various cancers with molecular cancer immune signaling pathways

\begin{tabular}{|c|c|c|c|c|c|}
\hline $\begin{array}{l}\text { Molecular } \\
\text { signaling } \\
\text { pathway } \\
\text { involved } \\
\text { in cancer } \\
\text { immune } \\
\text { regulation } \\
\text { at TME }\end{array}$ & Cancer & Target & Targeting agent & Inference & Reference \\
\hline \multirow{2}{*}{$\begin{array}{l}\beta \text {-catenin } \\
\text { signaling } \\
\text { pathway }\end{array}$} & \multirow[t]{2}{*}{$\begin{array}{l}\text { Metastatic } \\
\text { melanoma cancer }\end{array}$} & \multirow[t]{2}{*}{ Cancer cells } & \multirow{2}{*}{$\begin{array}{l}\text { Anti-PD-L1/ } \\
\text { anti-CTLA-4 } \\
\text { monoclonal } \\
\text { antibodies }\end{array}$} & $\begin{array}{l}\text { Relation between active WNT/ } \beta \text {-catenin } \\
\text { signaling and T-cell gene expression. }\end{array}$ & \multirow[t]{2}{*}{ [53] } \\
\hline & & & & $\begin{array}{l}\text { Inhibition of CCL4 secretion in cancer cells } \\
\text { mediate via transcriptional repressor ATF3 } \\
\text { under active WNT/ } \beta \text {-catenin signaling. }\end{array}$ & \\
\hline \multirow{3}{*}{$\begin{array}{l}\text { STAT3 } \\
\text { signaling } \\
\text { pathway }\end{array}$} & \multirow{2}{*}{$\begin{array}{l}\text { Human non-small } \\
\text { cell lung cancer } \\
\text { (NSCLC) }\end{array}$} & \multirow[t]{3}{*}{-} & \multirow[t]{3}{*}{-} & $\begin{array}{l}\text { Stat } 3 \text { has inhibitory effect on antitumor } \\
\text { NK cell. }\end{array}$ & \multirow[t]{3}{*}{ [54] } \\
\hline & & & & Activation pathway represented as Jak2/Stat3 & \\
\hline & Prostate cancer & & & pathway hinders antitumor immunity. & \\
\hline \multirow[t]{3}{*}{$\begin{array}{l}\text { PI3K/ } \\
\text { PTEN/ } \\
\text { AKT/ } \\
\text { mTOR } \\
\text { signaling } \\
\text { pathway }\end{array}$} & $\begin{array}{l}\text { Breast cancer } \\
\text { Prostate } \\
\text { carcinoma }\end{array}$ & Cancer cells & B7-H1 siRNA & $\begin{array}{l}\text { Reveals correlation between } \\
\text { immunoresistance T-cell mediated through } \\
\text { B7-H1 and active PI3k expression in cancer } \\
\text { where subsequent treatment with B7-H1 } \\
\text { siRNA drops the immunoresistant phenotype } \\
\text { in cancer cells. Further overexpression of } \\
\text { B7-H1 protein with lower PI3k expression } \\
\text { adopts the protumor nature. }\end{array}$ & [55] \\
\hline & $\begin{array}{l}\text { Lung } \\
\text { adenocarcinomas }\end{array}$ & \multirow{2}{*}{$\begin{array}{l}\text { Cancer cells } \\
\text { and antitumor } \\
\text { immune } \\
\text { response }\end{array}$} & \multirow[t]{2}{*}{$\begin{array}{l}\text { mTOR inhibitor + } \\
\text { PD-1 antibody }\end{array}$} & $\begin{array}{l}\text { Active involvement of oncogenic AKT-mTOR } \\
\text { signaling in regulation of PD-L1 expression. }\end{array}$ & \multirow[t]{2}{*}[56,57]{} \\
\hline & $\begin{array}{l}\text { Squamous cell } \\
\text { carcinomas }\end{array}$ & & & $\begin{array}{l}\text { Post treatment with mTOR inhibitor and PD-1 } \\
\text { antibody has targeted tumor and increased } \\
\text { the antitumor immune response. Intratumoral } \\
\text { injection of an AKT inhibitor also enhanced } \\
\text { the therapeutic efficacy of an E7-specific } \\
\text { vaccine or E7-specific CD }{ }^{+} T \text { cell adoptive } \\
\text { transfer against immune-resistant tumors. }\end{array}$ & \\
\hline
\end{tabular}


Table 2. Studies from various cancers with molecular cancer immune signaling pathways (continued)

\begin{tabular}{|c|c|c|c|c|c|}
\hline $\begin{array}{l}\text { Molecular } \\
\text { signaling } \\
\text { pathway } \\
\text { involved } \\
\text { in cancer } \\
\text { immune } \\
\text { regulation } \\
\text { at TME } \\
\end{array}$ & Cancer & Target & Targeting agent & Inference & Reference \\
\hline \multirow[t]{2}{*}{$\begin{array}{l}\text { p53 } \\
\text { signaling } \\
\text { pathway }\end{array}$} & $\begin{array}{l}\text { Liver carcinoma } \\
\text { Breast tumor }\end{array}$ & $\begin{array}{l}\text { Cancer, NK } \\
\text { cells and } \\
\text { infiltrating } \\
\text { lymphocytes }\end{array}$ & - & $\begin{array}{l}\text { Reveals tumor regression, associated with } \\
\text { restoration of wild type tumor suppressor } p 53 \\
\text { expression which enable recruitment of NK } \\
\text { cells driven by cytokine release. }\end{array}$ & [58] \\
\hline & & & & $\begin{array}{l}\text { Studies reveal mutational status of } \\
\text { tumor suppressor gene is correlated with } \\
\text { lymphocytic infiltration. }\end{array}$ & \\
\hline $\begin{array}{l}\text { NF-KB } \\
\text { signaling } \\
\text { pathway }\end{array}$ & Ovarian cancer & $\begin{array}{l}\text { DCs and } \\
\text { macrophages }\end{array}$ & $\begin{array}{l}\text { DHMEQ (NF-kB } \\
\text { inhibitor) }\end{array}$ & $\begin{array}{l}\text { Constitutive expression of NF-kB is symbolic } \\
\text { to oncogenic drive at TME. Subsequent } \\
\text { administration of DHMEQ (NF-kB inhibitor) } \\
\text { overcome the suppressed immune } \\
\text { response in human immune cells (DCs and } \\
\text { macrophages) when cultured in supernatant } \\
\text { derived from epithelial ovarian cancer cells. }\end{array}$ & [59] \\
\hline \multirow[t]{3}{*}{$\begin{array}{l}\text { RAS/RAF/ } \\
\text { MAPK } \\
\text { signaling } \\
\text { pathway }\end{array}$} & $\begin{array}{l}\text { Human lung } \\
\text { adenocarcinoma } \\
\text { (NSCLC cell } \\
\text { lines) }\end{array}$ & $\begin{array}{l}\text { Cancer and } \\
\text { adaptive } \\
\text { immune T } \\
\text { cells }\end{array}$ & $\begin{array}{l}\text { Anti-PD-1 } \\
\text { antibody } \\
\text { (pembrolizumab)/ } \\
\text { ERK inhibitor }\end{array}$ & $\begin{array}{l}\text { KRAS mutation introduced } \\
\text { immune suppression. } \\
\text { Targeting at p-ERK signaling reverses it. }\end{array}$ & {$[60]$} \\
\hline & Melanoma cancer & $\begin{array}{l}\text { Adaptive } \\
\text { immune cells }\end{array}$ & $\begin{array}{l}\text { Immune } \\
\text { checkpoint } \\
\text { blockers }+ \\
\text { inhibitors of MEK/ } \\
\text { BRAF }\end{array}$ & $\begin{array}{l}\text { Studies reveal role of BRAF mutation in } \\
\text { constitutive expression of MAPK pathway and } \\
\text { its impact on adaptive immune functioning, } \\
\text { blocking the same with respective pathway } \\
\text { inhibitors (MEK/BRAF) along with immune } \\
\text { checkpoint blockers reverses the protumor } \\
\text { immune functioning towards antitumor } \\
\text { response inhibiting tumor growth. }\end{array}$ & {$[38,61]$} \\
\hline & Melanoma cancer & MDSCs & BRAF inhibitors & $\begin{array}{l}\text { Presence of BRAF inhibitor reduces MDSC } \\
\text { infiltration but resistant to BRAF inhibitor } \\
\text { restores the same with activation of MAPK } \\
\text { signaling pathway, downstream regulation } \\
\text { focuses on increased myeloid attractant for } \\
\text { their recruitment at TME. }\end{array}$ & {$[41,62]$} \\
\hline
\end{tabular}

siRNA: small interfering RNA; -: not applicable

\section{Cancer immunotherapies, present status and concerns}

The conventional approaches for cancer management (chemotherapy, radiotherapy and surgery etc.) are majorly associated with tumor targeting. So, cancer immunotherapies require the advancement in the existing treatment strategies for better outcomes. Here, the potential approach can be directed towards cancer immune interactions and modulating immune response to fight back against progressive tumor growth. Several cancer immunotherapies are accepted for cancer treatment that are strategically employed for tumor regression goals with diverse routes of action. For ease of understanding, cancer immunotherapies can be categorized as, molecular immunotherapies (e.g., cytokine therapies and antibody therapies], cellular immunotherapies [e.g., adoptive cell transfer therapies, T cell receptor (TCR) T cells therapies, chimeric antigen receptor (CAR) T cells therapies] and vaccination immunotherapies (e.g., cancer immune vaccine). Here, current status of respective cancer immmunotherapies has been described along with their drawbacks $[63,64]$.

Currently, cytokine therapies are used as supporting treatment for cancer management. Cytokines such as IL-2 and IFN- $\alpha$ are Food and Drug Administration (FDA) approved for treatment of melanoma and renal cell carcinoma. High dose of IL-2 is administered to metastatic form of cancer, while IFN- $\alpha$ is 
applied as an adjuvant therapy for Stage III melanoma [63]. The pleiotropism and redundancy of cytokines in modulating signaling events possesses a major challenge in presenting cytokines as the mainstream cancer immunotherapies. Other challenges associated are limited toxicities and exemplified low response rates at the target site $[63,65]$. Role of antibody therapies as precise immuno-medicine in form of immune checkpoint inhibitors accurately monitors the immune checkpoint escape and obstructs negative regulations involved with immune response. Different antibodies can be selected for targeting either independently or in combination, therefore, blocking CTLA-4, the PD-1 and PD-L1 pathway or the LAG-3 pathway. Presence of such checkpoints focuses its potential ability on altering immune microenvironment and associated heterogeneity for several targets, for example, with similar receptor ligand interaction such as PD-L1/PD-R interaction, and the generated response might have a non-specific nature. Further, unclear interactions between LAG-3 and its associated ligands can also be misinterpreted as ineffective targeting response generated by blocker antibodies. This is also a major challenge which limits the applications of antibody-mediated immunotherapy for cancer management [66]. Further, adoptive cell transfer therapies overcome cancerous growth by supporting adaptive immune regulation, which utilizes immune cells, specifically $\mathrm{T}$ cells isolated from the patient or engineer them on genetic basis to work accordingly, further reinfuse them back into the patient's body for continual clonal repopulation of $\mathrm{T}$ cells, therefore eliminating cancerous growth. Currently, adoptive cell transfer therapies have attained considerable progress in targeting cancer malignancies. For genetically engineered T cells, these are represented as CAR T cells and TCR engineered T cells. Such modification has raised the acceptation levels of immune therapies. However, efficacy in delivering the antitumor immune response with immune stimulation is challenging, as it requires proper monitoring with minimum antigen loss and trafficking in a biological system [67]. Cancer vaccines are another form of cancer immunotherapies where tumor specific antigens (polypeptides, DNA and RNA) are exploited for building immunogenic response, which can trigger antitumor expressions, thereby, generating antitumor immunity with additional support from adjuvant molecules for improved tumor killing response. Different types of cancer vaccines are designed based on antigen types derived from various cells like tumor cells and DCs. This vaccination approach assembles the diverse immune mechanisms unambiguously destroying cancer cells. So, cancer vaccines offer key tactics for inhibition of advanced tumor growth and its recurrence [68]. Further, in several cases immunotherapies are provided as combination therapies conjugated with other adjuvant molecules (drugs or immunomodulators), but their presence can often be accompanied with other serious toxicities and might also experience failure in optimally activating the resident lymphocytes within TME and lymphoid compartments [69]. Oncolytic virus therapies (OVT) and its projection as an effective immunotherapy for cancer targeting is possible because of artificial viral construct. Despite of constructive delivery outcomes for cancer targeting, it has come up with various challenges. Few of these are rejections of OVT by activated immune response due to presence of virus as carrier system and an appropriate administered dose in some cases is marked with limited efficacy. So, there is a need to reveal an ideal equilibrium slit window, where immune antiviral response does not interfere with its therapeutic antitumor immune response [70].

\section{Nano-immunotherapeutic for cancer treatment}

Nanotechnology being interdisciplinary represents an innovative approach to design extremely effective combinational therapies enhancing the efficacy of immunotherapy and overcoming its barriers. Nanoparticles can be premeditated in several ways. Owing to their compositional plasticity, size and geometry, nanoparticles may be useful to overpower key points of immunotherapy, which include localized and controlled release of cytokines and stability of biomolecules enhancing availability after infusion. This may facilitate reduction of effective dose and regulate adverse immune-related responses. Literature survey indicates that nanoparticles preferentially accumulate passively at the tumor site through an enhanced permeability and retention (EPR) effect, owing to higher permeability of the angiogenic blood vessels of the solid tumor. Besides EPR, nanoparticles tend to use active processes to enter the solid tumors, primarily by trans-endothelial processes. To understand the molecular mechanisms involved in these active processes related to nanoparticle extravasation, clarity on the interaction of surface-properties of nanoparticles 
and nanoparticle-tumor endothelial cell interface will be quintessential. Moreover, nanoparticles can be engineered to aim at the active cellular targeting, and nanoparticles of ultrasmall dimensions can cross the physiological barriers, including blood brain barrier (BBB), and spread to the intricate TME, thereby enhancing drug delivery.
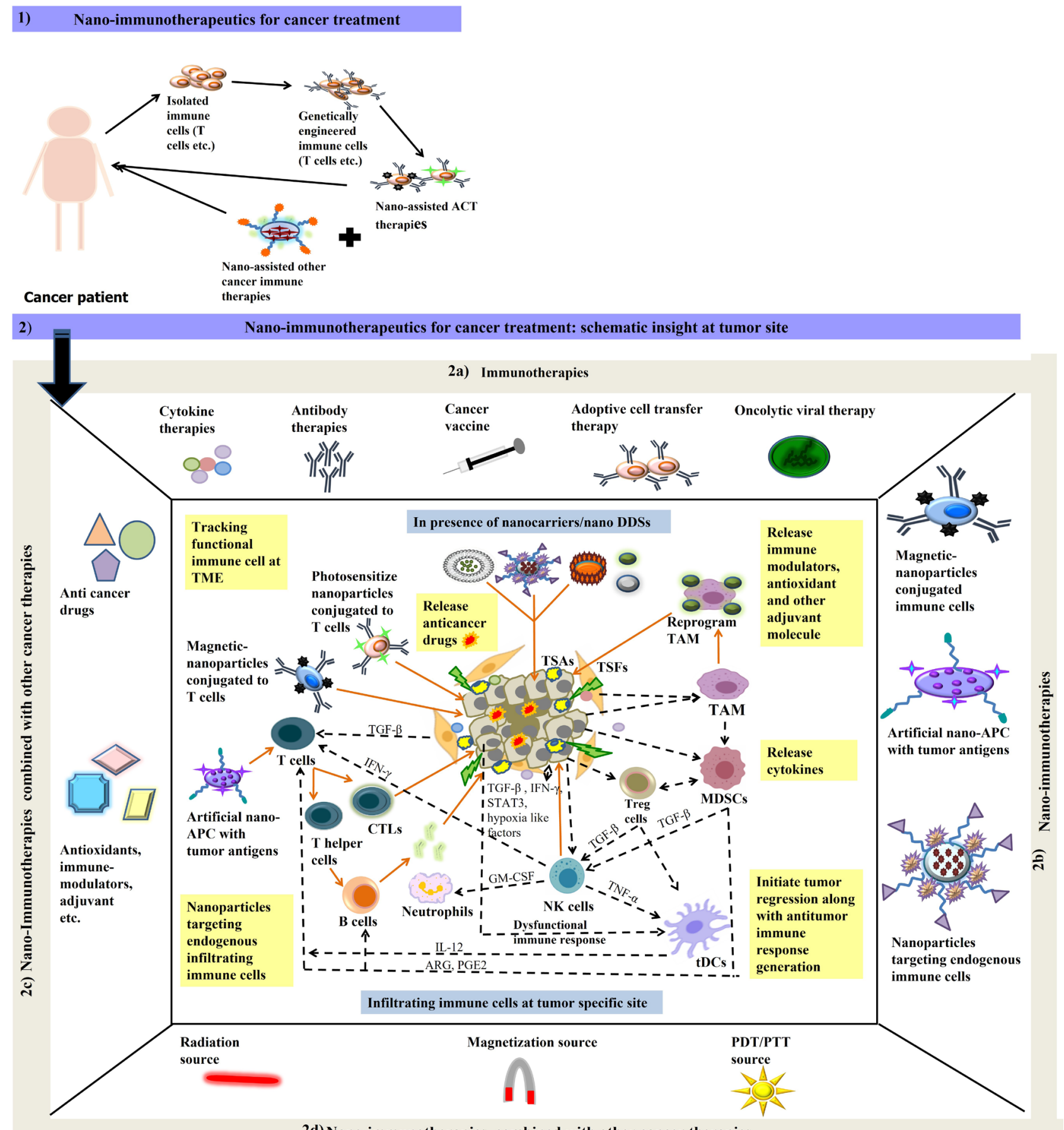

2d) Nano-immunotherapies combined with other cancer therapies

Figure 1. Schematic illustration of 1) nano-immunotherapeutics for cancer treatment in cancer patients; 2) nano-immunotherapeutics at tumor specific site where 2a) represent different types of immune therapies that are currently be employed for tumor targeting; $2 \mathrm{~b}$ ) represent nano-assisted immunotherapies applied as magnetic or photosensitized immune cell at TME, artificial nano-APCs for tumor antigen presentation and processing at TME for effective recruitment of adoptive immune cells; 2c) represent surface functionalized nanoparticles can also be employed for effective tumor regression activities either performed directly with encapsulated anticancer drug, antioxidant etc. or indirectly by overcoming suppressed immune response at TME with different immune modulating compounds and adjuvant molecules encapsulated in nano-drug delivery systems (DDSs) for cancer treatment; 2d) represent different combination approaches additional to nano-immunotherapies in form of radiation, photodynamic therapy/ photothermal therapy (PDT/PTT) or magnetized source for better cancer management. Dash lines in black color represent the existing crosstalk amongst different cells (cancer cells: TSFs, TSAs etc.); immune cells (TANs, TAMs, MDSCs, Tregs, T cells, $\mathrm{B}$ cells, NK cells etc.) at TME. Lines in orange color represent the probable route of action for nano-assisted immune therapies 
Usually, nanoparticles comprise a core, in which drugs are encapsulated, and an outer shell, where the external layer is functionalized. This structure permits several drugs to be simultaneously carried and delivered to the target site, thus augmenting combinatorial therapeutic strategies. The amalgamation of immunotherapy and nanomedicine may improve the efficacy of single conventional therapy and can emerge as cost effective carriers [71, 72]. However, undesired immune reactions are triggered by the high reactivity and poor stability of nanoparticles that cause loss of cargo in blood. Therefore, to overcome these limitations the design of nanoparticles must focus upon its characteristics such as surface morphology and size, its uptake or internalization process, release mechanism for better biodistribution, biocompatibility and pharmacokinetics [73-75]. Further, doing so will reprogram or introduce functional modulation in antitumor immune response generated at TME [76, 77] (Figure 1).

\section{Nano-assisted cytokine therapies}

Nanocarriers encapsulating cytokines can help cytokine therapies to be included as mainstream therapies, as they can assist in overpowering the challenges of the intricate TME. With an in-depth understanding of the multifaceted antitumor response mediated by cytokines, nano-assisted cytokine therapies can emerge as frontrunner in nano-immunotherapies $[78,79]$. Shen and coworkers [80] worked on effective delivery of trap genes IL-10 trap and CXCL12 trap, these were encapsulated into lipid protamine DNA (LPD) nanoparticles and was delivered to TME in 4T1 breast cancer mouse model. This nano-DDSs boosted infiltrating response of CTLs along with enhanced antitumor activity of other immune cells such as tDCs, NK cells, and macrophages to promote tumor regression. Further, Curnis along with coworkers [81] has demonstrated effectiveness of surface functionalized Au nanoparticles (AuNPs) for tumor targeting in fibrosarcoma mouse (BALB/c) model. Functionalized AuNPs were tagged with peptide comprising asparagine-glycine-arginine (NGR) motif and TNF in a well decorated form. The former peptide acts as a driving agent for TNF to reach at target tumor site, where it initiates its antitumor immune response with minimized toxicity to nearby surrounding tissue. Wang et al. [82] have focused on targeting strategies for solid tumors and have synthesized poly ( $\beta$-amino ester) copolymer nanoparticles (P1) loaded with interleukin IL-12 (IL-12ᄃP1). Delivery of this nanoformulation through intravenous route initiates antitumor response, and it also reprograms the TAM at TME with macrophage polarization achieved through immune modulation in solid tumors. Li and colleagues [83] demonstrated poly ( $d, l$-lactide-co-glycolide) nanoparticles surface functionalized with CD8 and glypican-3 antibodies and encapsulated with IL-12 was significant enough in regulating functional antitumor $\mathrm{T}$ cell response against hepatocellular carcinoma G2 (HepG2) liver cancer cells with rapid identification of surface marker and immediate release of encapsulated IL-12 cytokine at site of action.

\section{Nano-assisted antibody therapies}

Presence of nanocarriers can lend a hand to antibody therapies to overcome unusual responses, since its tendency to modify immune microenvironment and related heterogeneity can be redirected to desired target site at TME [84]. Wei and coworkers [85] demonstrated efficacy of chemo-immunotherapy for cancer targeting in well-defined nanocarriers system. For this, chemotherapeutic drug doxorubicin and immune adjuvant imiquimod (IMQ), a toll-like receptor 7 (TLR7) agonist were loaded in low molecular weight heparin (LMWH)- $d$ - $\alpha$-tocopheryl succinate (TOS) micelles (LT) along with anti-PD-L1. Targeting of immune checkpoints through PD-L1/PD-1 axis in immune cells triggers the activation of DCs, with an increased ratio of $\mathrm{CD} 8^{+}$CTLs to CD $4^{+} \mathrm{T}$ effector cells. Further, Wang and colleagues [86] proved the potential role of PTT along with nano-immunotherapy. Here, surface functionalized CuS NPs were initially modified with maleimide polyethylene glycol, and the presence of anti-PD-L1 as checkpoint blocker in nanocarrier system resulted in noticeable increase in the levels of inflammatory cytokines. This strategic targeting achieved by active CD8 ${ }^{+} \mathrm{T}$ cells was remarkable against the primary and distant tumor in $4 \mathrm{~T} 1$ mouse model. Duan and coworkers [87] designed Zn pyrophosphate (ZnP) nanoparticles loaded with photosensitizer (pyrolipid) and anti-PD-L1 blocker to potentiate immune therapeutic responses by actively targeting innate and adaptive immune cells at TME. Wang and colleagues [88] reported synergistic antitumor 
immune response generation in metastasizing cancer when treated with carbon nanotubes (CNTs) loaded with anti-CTLA-4 antibodies along with photothermal therapy. Further, Mi and coworkers [89] employed combinational immunotherapy approach for cancer targeting, where NPs were conjugated with antagonistic antibodies $\alpha$ PD1 and agonistic antibodies antitumor necrosis factor receptor superfamily member 4 $(\alpha 0 X 40)$, and the two were co-administered with spatiotemporal precision for enhanced efficacy in tumor models. Doing so initiates optimal activation of T cell via immunomodulatory mechanism when compared to respective controls (free antibody as immunotherapy). Wang and coworkers [90] designed $\mathrm{pH}$ responsive dextran NPs integrated with hyaluronic acid, loaded with anti-PD-1 (aPD1) and glucose oxidase (GOx). The low pH of TME promotes self-dissociation of intratumoral injected dextran NPs causing the release of aPD1 that subsequently induces robust immune response as compared to plain aPD1. This administration strategy integrated with immunomodulators can be used as combinatorial immunomodulation approach for improved efficacy against tumors.

\section{Nano-assisted adoptive cell transfer therapies}

Adoptive $\mathrm{T}$ cell transfer has been exploited to eliminate solid tumors, but the clinical results have been disappointing owing to limited T cell expansion within the immunosuppressive TME. Nanocarriers can target specific subsets of immune cells within the TME. T cells are found within the TME, and higher cytotoxic T cell infiltration is frequently correlated with improved survival, while increased numbers of Tregs may be related with the worst prognosis.

Nanocarriers offer protection to $\mathrm{T}$ cells from immunosuppressive signals that can improve the $\mathrm{T}$ cell infiltrations within TME [91, 92]. Zheng and coworkers [93] have designed nanocarriers for effective adoptive cell transfer therapy. Here, IL-2 Fc-PEGylated liposomes and anti-Thy1.1-PEGylated liposomes performed dual action by stimulating and tracking adoptive cell therapy (ACT) $\mathrm{T}$ cells in tumor bearing mouse model. These outcomes exhibit the possibility for purposeful and quick reprogramming of targeting lymphocytes through engineered nanocarrier system. Smith and coworkers [94] demonstrated that DNA within synthesized polymeric nanocarriers can target and reprogram CAR genes in T cells extracted from leukemia cancer patient. Further reinfusing them will build a strong antitumor immune response in $\mathrm{T}$ cells to combat against progressive tumor growth. Generally, the synthesized nanocarriers were capable of producing activation, proliferation, and memory response in T cells. Such nanocarriers can provide broad realistic applications and purposeful clinical approach for cancer management. Fadel and colleagues [95] reveal strategic expansion of T cells with nanocarriers working as artificial APCs for adoptive therapies. Here, nanocomposites of CNT and polymers were ornamented with antigens and IL-2 specific for T cell activation. Such presentation of nanocarrier has encouraged as a promising approach for tumor regression in melanoma murine model. The surface engineered CAR T cells designed to deliver adenosine antagonist encapsulated in liposomal nanoparticles within TME of solid tumors and obstruct immunosuppressive response in antitumor immune cells [96]. Chen with coworkers [97] proved that the presence of indocyanine green (ICG) in poly(lactic-co-glycolic) acid (PLGA) nanoparticles can promote enhanced recruitment of CAR $\mathrm{T}$ cell for superior antitumor immune activity at TME in melanoma tumors model with photothermal therapy. However, further research investigation in this direction by Nie and colleagues [98] demonstrated that magnetic nanoclusters can also be employed for similar work with technical assistance as applied neodymium magnet. This represents improved enrollment of nanocluster $\mathrm{T}$ cells to tumor specific site where they undergo disassembling of nanocluster, thus encouraging antitumor effects of $\mathrm{T}$ cells at TME.

\section{Nano-assisted cancer vaccines}

Nanocarriers will enable loading or encapsulation of the cancer vaccines that are specially designed based on tumor specific antigen. Apart from the physical and chemical attributes of nanocarriers, other potential features that focus on multiple deliveries wherein multiple attributes can be targeted through an administered route required for effective nano-immunotherapy. This includes immunomodulatory or adjuvant molecules coupled with tumor antigens, raising the levels of nano-immunotherapy [99-101]. Studies in in vivo melanoma mouse model demonstrate antitumor 
and immunoregulatory nature of melittin (specialized bee venom from Europe). But its encapsulation in lipid nanoparticles enables effective targeting of cancer in primary and metastatic melanoma via modulated antitumor immune response in lymph nodes, where activated TAAs are presented by macrophages and dendritic cells to $\mathrm{CD}^{+} \mathrm{T}$ cell generating effector immune response $[102,103]$. Thus, it can be considered as a potent nano-vaccine for treatment of breast and other cancers [104]. Nguyen et al. [105] have synthesized nano-vaccine composed of silica nanorods and silica nanoparticles clustered together, loaded with ovalbumin (OVA) protein antigen, immune adjuvant granulocyte macrophage colony-stimulating factor (chemokine), TLR9 agonist (CpG oligo-deoxynucleotides, CpG-ODNs) for effective recruitment of activated DC in myeloma mouse model. Further, its synergistic nature upon treatment with immune checkpoint anti-CTLA-4 (a-CTLA-4) also reveals its efficacy in tumor mouse model. Zamani et al. [106] have studied human epidermal growth factor 2 (HER2/neu) and a Pan HLA-DR (PADRE) tumor's specific long epitope (peptide) on conjugation with nanoliposomes. These nanoformulations were administered subcutaneously to HER2 ${ }^{+}$TUBO breast cancer mice model and their potential role as an effective nano-vaccine was reported as they enhanced helper T cell and CTL immune responses via activated DC expression against metastatic growth. Masjedi and coworkers [107] demonstrated antitumor immune responses in $4 \mathrm{~T} 1$ breast tumor mice model (Balb/C) where, siRNA for adenosine type 2 receptors signaling were loaded into polymeric nanoparticles [polyethylene glycol (PEG)-chitosan-lactate (PCL)]. This signaling was known to interfere with the function [down regulation of adenosine $A_{2 A}$ receptor (A2AR)] and differentiation (silencing of naive T cell $C D 4^{+}\left(D 25^{-}\right.$) response generated by T cells. Successive immune stimulation, post treatment with polymeric nanoformulation was a resultant of immune signaling event. Where downregulation of protein kinase A/cAMP-response element binding protein (PKA/CREB) occurs and upregulation of NF- $\kappa B$ enhances antitumor performance of $\mathrm{T}$ cells at TME. Another study led by Jadidi-Niaragh and coworkers [108] demonstrated CD73 as a leading immune suppressive agent related to adenosine levels. The intravenous administration and targeting of adenosine levels by CD73 siRNA-loaded chitosan-lactate nanoparticles and tumor lysate pulse DCs vaccine has illustrated immense efficacy against tumor growth by reducing the immune suppressive activities of protumor immune cells (Treg, MDSCs, TAMs etc.) at TME. Liu et al. [109] worked on synergistic administration of curcumin loaded poly( $\varepsilon$-caprolactone-co-1,4,8-trioxa[4.6]spiro-9-undecanone)poly(ethyleneglycol)-poly( $\varepsilon$-caprolactone-co-1,4,8-trioxa[4.6]spiro-9-undecanone (PECT) polymeric nanoparticles and nano-vaccine loaded with $\mathrm{CpG}$ and antigenic peptides that triggered immunogenic cancer cell death (ICD) in TME through immune stimulatory and cytotoxic immune response initiation in DCs and CD8 ${ }^{+} \mathrm{T}$ cells in $4 \mathrm{~T} 1$ breast cancer model. This greatly signifies the efficacy of nano-assisted chemo-immunotherapeutics for treatment of breast and other cancers.

\section{Nano-assisted oncolytic virus therapies}

Recent reports for potential role of nanotechnologies in providing platform as oncolytic virus therapies have initiated neo-trends in cancer nano-immunotherapies where these nano-assisted oncolytic virus therapies can prevail over the limitations thus making virus nanocarriers safer, efficient and potent for cancer patients [110,111]. Work led by Lizotte and coworkers [112] demonstrated that cowpea mosaic virus (CPMV) used as nanoparticles which was administered via inhalation in different cancer models (B16F10 lung melanoma, ovarian, colon, and breast tumor models), where its efficacy was attained through systemic activation of the immune responses. Efficiency of the antitumor immune responses of CPMV nanoparticles was primarily due to its stable and nontoxic nature. Flexibility in the desired cargo through drug/antigen loading or nano fabrication has attracted researchers and clinicians as novel approach to target immune responses against metastatic cancer. Further, Arab and coworkers $[113,114]$ have demonstrated the role of phage nanoparticles in breast cancer where coat protein gpD of lambda phage ( $\lambda F 7$ ) nanoparticles was linked to HER2 protein (E75 and AE37 peptide). In vitro studies along with effective delivery in HER $^{+}$TUBO breast cancer Balb/c mouse model were also evident. 


\section{Conclusions}

The past decade has witnessed treatment modalities ranging from chemotherapy, radiotherapy, photodynamic and photothermal therapy, that have been exploited to elicit antitumor activities. Cancer immunotherapy has attracted extensive attention due to its ability to activate the innate or adaptive immune systems to combat tumors in patients. However, immunotherapy is severely limited, as it can neither elicit a long-term antitumor immune response nor can it restrict the severe systemic toxicity. To address these challenges, nano-immunotherapeutics or nanomedicine-based drug delivery systems have been exploited to improve cancer immunotherapy by delivering to specific immune cell subsets. Nanotechnology integrates several functions within precise shape and size, therefore, it has unique features for improving immunotherapy.

Tumors are exceedingly heterogeneous and nurture a complex microenvironment that consists of ECM, fibroblasts, a leaky vasculature and immune cells. It is crucial to develop nanoparticles that can adapt the TME and improve the selective targeting of anti-cancer drugs to tumors. Nano-assisted medicines offer the likelihood to switch the immune system "on and off" at any given time to increase the efficacy and minimalize the adverse effects; several nanomedicines have shown prominent outcomes in the diseased animal models, but not as yet in human trials.

In this review, we have summarized how nanoparticles act as an effective DDS when altered with several ligands that can precisely target factors in TME comprising fibroblasts, macrophages, tumor vasculature and DCs. Besides, nanoparticles can manipulate the abnormal functions and assemblies of TME, thus circumventing development of drug resistance and amplifying the therapeutic results of radiotherapy, chemotherapy and PDT. Although NPs tend to accumulate in the TME, the intratumoral NPs can either be captured by non-specific cells or sequestered by the ECM. Immune cells can assist the NPs to target tumor cells therefore forcing the TME to enhance accumulation in otherwise inaccessible tumor sites. T cells can be used to carry the immune-boosting agents to tumors, and other immune cells such as macrophages and dendritic cells can also be potentially used as "Trojan horses". Preliminary successes regarding nanomedicines in clinics have shown great promise, however, a few unresolved challenges remain. The high payload, enhanced stability in circulation, tumor specific targeting, increased cost of manufacturing, and reproducibility in industry-scale production can definitely assist the translation of nanomedicines to clinics. With an improvement in understanding of cancer biology and cancer research, nano-assisted immunotherapy will surely transform the treatment modalities and prognosis of advanced malignancies in the near future.

\section{Abbreviations}

AKT: protein kinase B

APCs: antigen presenting cells

B cells: B lymphocytes cells

CAR: chimeric antigen receptor

CCLs: C-C motif chemokine ligands

CTLA-4: cytotoxic T lymphocyte associated antigen 4

CTLs: cytotoxic T lymphocytes

CXCL10: C-X-C motif chemokine ligand 10

DCs: dendritic cells

EGFR: epidermal growth factor receptor

FGF: fibroblast growth factor

HER2: human epidermal growth factor 2

IDO: indoleamine 2, 3-dioxygenase

IFN- $\gamma$ : interferon- $\gamma$ 
IL-10: interleukin-10

$L A G$-3: lymphocyte-activation gene 3

MDSCs: myeloid derived suppressor cells

MHC: major histocompatibility complex

MMPs: matrix metalloproteinases

mTOR: mammalian target of rapamycin

NF-кB: nuclear factor kappa-light-chain enhancer of activated B cells

NK: natural killer

NSCLC: non-small cell lung cancer

PD-1: programmed cell death 1

PD-L1: programmed death-ligand 1

PI3K: phosphoinositide-3-kinase

PTEN: phosphatase and tensin homolog

RAF: rapidly accelerated fibrosarcoma

RAS: rat sarcoma virus

ROS: reactive oxygen species

siRNA: small interfering RNA

STAT3: signal transducer and activator of transcription 3

T cells: $\mathrm{T}$ lymphocytes cells

TAMs: tumor associated macrophages

TANs: tumor associated neutrophils

tDCs: tolerogenic dendritic cells

TGF- $\beta$ : transforming growth factor- $\beta$

Th1: T helper type 1

TILs: tumor infiltrating lymphocytes

TME: tumor microenvironment

TNF: tumor necrosis factor

TRAIL: tumor necrosis factor-related apoptosis-inducing ligand

Tregs: T regulatory cells

TSAs: tumor specific adipocytes

TSECs: tumor specific endothelial cells

TSFs: tumor specific fibroblasts

TSPs: tumor specific pericytes

VEGF: vascular endothelial growth factor

\section{Declarations}

\section{Acknowledgments}

PS acknowledges UGC, India for the assistance in form of fellowship. MY and KN acknowledge CSIR, India for the assistance in form of fellowship.

\section{Author contributions}

PS, MY, KN and AKV conceived and wrote the manuscript. AKV edited the manuscript. All authors contributed to manuscript writing, revision, read and approved the submitted version. 


\section{Conflicts of interest}

The authors declare that they have no conflict of interest.

\section{Ethical approval}

Not applicable.

\section{Consent to participate}

Not applicable.

Consent to publication

Not applicable.

Availability of data and materials

Not applicable.

\section{Funding}

Not applicable.

\section{Copyright}

(C) The Author(s) 2022.

\section{References}

1. Ferlay J, Colombet M, Soerjomataram I, Parkin DM, Piñeros M, Znaor A, et al. Cancer statistics for the year 2020: an overview. Int J Cancer. 2021;2021;149:778-89.

2. Labani-Motlagh A, Ashja-Mahdavi M, Loskog A. The tumor microenvironment: a milieu hindering and obstructing antitumor immune responses. Front Immunol. 2020;11:940.

3. Jiang X, Wang J, Deng X, Xiong F, Zhang S, Gong Z, et al. The role of microenvironment in tumor angiogenesis. J Exp Clin Cancer Res. 2020;39:204.

4. Gonzales Carazas MM, Pinto JA, Casado FL. Biological bases of cancer immunotherapy. Expert Rev Mol Med. 2021;23:e3.

5. Ventola CL. Cancer immunotherapy, part 3: challenges and future trends. P T. 2017;42:514-21.

6. Date A, Nikam VS, Syed S, Sawarkar SP. Future immunotherapy challenges and perspectives. In: Sawarkar SP, Nikam VS, Syed S, editors. Immunotherapy—a novel facet of modern therapeutics. Singapore: Springer; 2020. pp. 247-62.

7. Gong F, Yang N, Wang X, Zhao Q, Chen Q, Liu Z, et al. Tumor microenvironment-responsive intelligent nanoplatforms for cancer theranostics. Nano Today. 2020:32;100851.

8. Sun Q, Bai X, Sofias AM, van der Meel R, Ruiz-Hernandez E, Storm G, et al. Cancer nanomedicine meets immunotherapy: opportunities and challenges. Acta Pharmacol Sin. 2020;41:954-8.

9. Yang M, Li J, Gu P, Fan X. The application of nanoparticles in cancer immunotherapy: targeting tumor microenvironment. Bioact Mater. 2020;6:1973-87.

10. Baghban R, Roshangar L, Jahanban-Esfahlan R, Seidi K, Ebrahimi-Kalan A, Jaymand M, et al. Tumor microenvironment complexity and therapeutic implications at a glance. Cell Commun Signal. 2020;18:59.

11. Nieman KM, Romero IL, Van Houten B, Lengyel E. Adipose tissue and adipocytes support tumorigenesis and metastasis. Biochim Biophys Acta. 2013;1831:1533-41.

12. Zhao Q, Eichten A, Parveen A, Adler C, Huang Y, Wang W, et al. Single-cell transcriptome analyses reveal endothelial cell heterogeneity in tumors and changes following antiangiogenic treatment. Cancer Res. 2018;78:2370-82.

13. Maishi N, Hida K. Tumor endothelial cells accelerate tumor metastasis. Cancer Sci. 2017;108:1921-6. 
14. Liu T, Zhou L, Li D, Andl T, Zhang Y. Cancer-associated fibroblasts build and secure the tumor microenvironment. Front Cell Dev Biol. 2019;7:60.

15. Binnewies M, Roberts EW, Kersten K, Chan V, Fearon DF, Merad M, et al. Understanding the tumor immune microenvironment (TIME) for effective therapy. Nat Med. 2018;24:541-50.

16. Sadeghi Rad H, Monkman J, Warkiani ME, Ladwa R, O'Byrne K, Rezaei N, et al. Understanding the tumor microenvironment for effective immunotherapy. Med Res Rev. 2021;41:1474-98.

17. Giese MA, Hind LE, Huttenlocher A. Neutrophil plasticity in the tumor microenvironment. Blood. 2019;133:2159-67.

18. Zhou J, Tang Z, Gao S, Li C, Feng Y, Zhou X. Tumor-associated macrophages: recent insights and therapies. Front Oncol. 2020;10:188.

19. Pan Y, Yu Y, Wang X, Zhang T. Tumor-associated macrophages in tumor immunity. Front Immunol. 2020;11:583084.

20. Yang Y, Li C, Liu T, Dai X, Bazhin AV. Myeloid-derived suppressor cells in tumors: from mechanisms to antigen specificity and microenvironmental regulation. Front Immunol. 2020;11:1371.

21. Kim JH, Kim BS, Lee SK. Regulatory T cells in tumor microenvironment and approach for anticancer immunotherapy. Immune Netw. 2020;20:e4.

22. DeVito NC, Plebanek MP, Theivanthiran B, Hanks BA. Role of tumor-mediated dendritic cell tolerization in immune evasion. Front Immunol. 2019;10:2876.

23. Fu C, Jiang A. Dendritic cells and CD8 T cell immunity in tumor microenvironment. Front Immunol. 2018;9:3059.

24. Melaiu O, Lucarini V, Cifaldi L, Fruci D. Influence of the tumor microenvironment on NK cell function in solid tumors. Front Immunol. 2020;10:3038.

25. Yang L, Li A, Lei $Q$, Zhang Y. Tumor-intrinsic signaling pathways: key roles in the regulation of the immunosuppressive tumor microenvironment. J Hematol Oncol. 2019;12:125.

26. Spranger S, Gajewski TF. Tumor-intrinsic oncogene pathways mediating immune avoidance. Oncoimmunology. 2015;5:e1086862.

27. Yaguchi T, Goto Y, Kido K, Mochimaru H, Sakurai T, Tsukamoto N, et al. Immune suppression and resistance mediated by constitutive activation of Wnt/ $\beta$-catenin signaling in human melanoma cells. J Immunol. 2012;189:2110-7.

28. Holtzhausen A, Zhao F, Evans KS, Tsutsui M, Orabona C, Tyler DS, et al. Melanoma-derived Wnt5a promotes local dendritic-cell expression of IDO and immunotolerance: opportunities for pharmacologic enhancement of immunotherapy. Cancer Immunol Res. 2015;3:1082-95.

29. Toso A, Revandkar A, Di Mitri D, Guccini I, Proietti M, Sarti M, et al. Enhancing chemotherapy efficacy in Pten-deficient prostate tumors by activating the senescence-associated antitumor immunity. Cell Rep. 2014;9:75-89.

30. Mittendorf EA, Philips AV, Meric-Bernstam F, Qiao N, Wu Y, Harrington S, et al. PD-L1 expression in triple-negative breast cancer. Cancer Immunol Res. 2014;2:361-70.

31. Parsa AT, Waldron JS, Panner A, Crane CA, Parney IF, Barry JJ, et al. Loss of tumor suppressor PTEN function increases B7-H1 expression and immunoresistance in glioma. Nat Med. 2007;13:84-8.

32. Garcia AJ, Ruscetti M, Arenzana TL, Tran LM, Bianci-Frias D, Sybert E, et al. Pten null prostate epithelium promotes localized myeloid-derived suppressor cell expansion and immune suppression during tumor initiation and progression. Mol Cell Biol. 2014;34:2017-28.

33. Wang G, Lu X, Dey P, Deng P, Wu CC, Jiang S, et al. Targeting YAP-dependent MDSC infiltration impairs tumor progression. Cancer Discov. 2016;6:80-95.

34. Cui Y, Guo G. Immunomodulatory function of the tumor suppressor p53 in host immune response and the tumor microenvironment. Int J Mol Sci. 2016;17:1942. 
35. Guo G, Yu M, Xiao W, Celis E, Cui Y. Local activation of p53 in the tumor microenvironment overcomes immune suppression and enhances antitumor immunity. Cancer Res. 2017;77:2292-305.

36. Iannello A, Thompson TW, Ardolino M, Lowe SW, Raulet DH. p53-dependent chemokine production by senescent tumor cells supports NKG2D-dependent tumor elimination by natural killer cells. J Exp Med. 2013;210:2057-69.

37. Tilborghs S, Corthouts J, Verhoeven Y, Arias D, Rolfo C, Trinh XB, et al. The role of nuclear factor-kappa B signaling in human cervical cancer. Crit Rev Oncol Hematol. 2017;120:141-50.

38. Chen N, Fang W, Lin Z, Peng P, Wang J, Zhan J, et al. KRAS mutation-induced upregulation of PD-L1 mediates immune escape in human lung adenocarcinoma. Cancer Immunol Immunother. 2017;66:1175-87.

39. Ott PA, Bhardwaj N. Impact of MAPK pathway activation in $\mathrm{BRAF}^{\mathrm{V} 600}$ melanoma on $\mathrm{T}$ cell and dendritic cell function. Front Immunol. 2013;4:346.

40. Zdanov S, Mandapathil M, Abu Eid R, Adamson-Fadeyi S, Wilson W, Qian J, et al. Mutant KRAS conversion of conventional T cells into regulatory T cells. Cancer Immunol Res. 2016;4:354-65.

41. Shabaneh TB, Molodtsov AK, Steinberg SM, Zhang P, Torres GM, Mohamed GA, et al. Oncogenic BRAFV600E governs regulatory T-cell recruitment during melanoma tumorigenesis. Cancer Res. 2018;78:5038-49.

42. Koyama S, Akbay EA, Li YY, Aref AR, Skoulidis F, Herter-Sprie GS, et al. STK11/LKB1 deficiency promotes neutrophil recruitment and proinflammatory cytokine production to suppress T-cell activity in the lung tumor microenvironment. Cancer Res. 2016;76:999-1008.

43. Li L, Yang L, Cheng S, Fan Z, Shen Z, Xue W, et al. Lung adenocarcinoma-intrinsic GBE1 signaling inhibits antitumor immunity. Mol Cancer. 2019;18:108.

44. Kortlever RM, Sodir NM, Wilson CH, Burkhart DL, Pellegrinet L, Brown Swigart L, et al. Myc cooperates with Ras by programming inflammation and immune suppression. Cell. 2017;171:1301-15.e14.

45. Zhang N, Zeng Y, Du W, Zhu J, Shen D, Liu Z, et al. The EGFR pathway is involved in the regulation of PD-L1 expression via the IL-6/JAK/STAT3 signaling pathway in EGFR-mutated non-small cell lung cancer. Int J Oncol. 2016;49:1360-8.

46. Concha-Benavente F, Srivastava RM, Trivedi S, Lei Y, Chandran U, Seethala RR, et al. Identification of the cell-intrinsic and-extrinsic pathways downstream of EGFR and IFN $\gamma$ that induce PD-L1 expression in head and neck cancer. Cancer Res. 2016;76:1031-43.

47. Zhang W, Pang Q Yan C, Wang Q, Yang J, Yu S, et al. Induction of PD-L1 expression by epidermal growth factor receptor-mediated signaling in esophageal squamous cell carcinoma. Onco Targets Ther. 2017;10:763-71.

48. Janse van Rensburg HJ, Azad T, Ling M, Hao Y, Snetsinger B, Khanal P, et al. The Hippo pathway component TAZ promotes immune evasion in human cancer through PD-L1. Cancer Res. 2018;78:1457-70.

49. Moroishi T, Hayashi T, Pan WW, Fujita Y, Holt MV, Qin J, et al. The Hippo pathway kinases LATS1/2 suppress cancer immunity. Cell. 2016;167:1525-39.e17.

50. Hennequart M, Pilotte L, Cane S, Hoffmann D, Stroobant V, Plaen E, et al. Constitutive IDO1 expression in human tumors is driven by cyclooxygenase- 2 and mediates intrinsic immune resistance. Cancer Immunol Res. 2017;5:695-709.

51. Moretti S, Menicali E, Nucci N, Voce P, Colella R, Melillo RM, et al. Signal transducer and activator of transcription 1 plays a pivotal role in RET/PTC3 oncogene-induced expression of indoleamine 2, 3-dioxygenase 1. J Biol Chem. 2017;292:1785-97.

52. Zhang X, Rao A, Sette P, Deibert C, Pomerantz A, Kim WJ, et al. IDH mutant gliomas escape natural killer cell immune surveillance by downregulation of NKG2D ligand expression. Neuro Oncol. 2016;18:1402-12.

53. Pai SG, Carneiro BA, Mota JM, Costa R, Leite CA, Barroso-Sousa R, et al. Wnt/beta-catenin pathway: modulating anticancer immune response. J Hematol Oncol. 2017;10:101. 
54. Ihara S, Kida H, Arase H, Tripathi LP, Chen YA, Kimura T, et al. Inhibitory roles of signal transducer and activator of transcription 3 in antitumor immunity during carcinogen-induced lung tumorigenesis. Cancer Res. 2012;72:2990-9.

55. Crane CA, Panner A, Murray JC, Wilson SP, Xu H, Chen L, et al. PI (3) kinase is associated with a mechanism of immunoresistance in breast and prostate cancer. Oncogene. 2009;28:306-12.

56. Xu C, Fillmore CM, Koyama S, Wu H, Zhao Y, Chen Z, et al. Loss of Lkb1 and Pten leads to lung squamous cell carcinoma with elevated PD-L1 expression. Cancer Cell. 2014;25:590-604.

57. Lastwika KJ, Wilson W 3rd, Li QK, Norris J, Xu H, Ghazarian SR, et al. Control of PD-L1 expression by oncogenic activation of the AKT-mTOR pathway in non-small cell lung cancer. Cancer Res. 2016;76:227-38.

58. Quigley D, Silwal-Pandit L, Dannenfelser R, Langerød A, Vollan HK, Vaske C, et al. Lymphocyte invasion in IC10/basal-like breast tumors is associated with wild-type TP53. Mol Cancer Res. 2015;13:493-501.

59. Nishio H, Yaguchi T, Sugiyama J, Sumimoto H, Umezawa K, Iwata T, et al. Immunosuppression through constitutively activated NF- $\mathrm{KB}$ signalling in human ovarian cancer and its reversal by an NF-кB inhibitor. Br J Cancer. 2014;110:2965-74.

60. Coelho MA, de Carné Trécesson S, Rana S, Zecchin D, Moore C, Molina-Arcas M, et al. Oncogenic RAS signaling promotes tumor immunoresistance by stabilizing PD-L1 mRNA. Immunity. 2017;47:1083-99.e6.

61. Ott PA, Henry T, Baranda SJ, Frleta D, Manches O, Bogunovic D, et al. Inhibition of both BRAF and MEK in $\mathrm{BRAF}^{\mathrm{V} 600 \mathrm{E}}$ mutant melanoma restores compromised dendritic cell (DC) function while having differential direct effects on DC properties. Cancer Immunol Immunother. 2013;62:811-22.

62. Steinberg SM, Shabaneh TB, Zhang P, Martyanov V, Li Z, Malik BT, et al. Myeloid cells that impair immunotherapy are restored in melanomas with acquired resistance to BRAF inhibitors. Cancer Res. 2017;77:1599-610.

63. Liu M, Guo F. Recent updates on cancer immunotherapy. Precis Clin Med. 2018;1:65-74.

64. Oiseth SJ, Aziz MS. Cancer immunotherapy: a brief review of the history, possibilities, and challenges ahead. J Cancer Metastasis Treat. 2017;3:250-61.

65. Wu F. New development of immune checkpoints blockade in cancer immunotherapy. E3S Web Conf. 2019;131:01022.

66. Makuku R, Khalili N, Razi S, Keshavarz-Fathi M, Rezaei N. Current and future perspectives of PD-1/PDL-1 blockade in cancer immunotherapy. J Immunol Res. 2021;2021:6661406.

67. Gorabi AM, Hajighasemi S, Sathyapalan T, Sahebkar A. Cell transfer-based immunotherapies in cancer: a review. IUBMB life. 2020;72:790-800.

68. Khodaei T, Sadri B, Nouraein S, Vahedi N, Mohammadi J. Cancer vaccination: various platforms and recent advances. J Immuno Biol. 2020;5:151.

69. Banstola A, Jeong JH, Yook S. Immunoadjuvants for cancer immunotherapy: a review of recent developments. Acta Biomater. 2020;114:16-30.

70. Marelli G, Howells A, Lemoine NR, Wang Y. Oncolytic viral therapy and the immune system: a double-edged sword against cancer. Front Immunol. 2018;9:866.

71. Mi Y, Hagan CT 4th, Vincent BG, Wang AZ. Emerging nano-/microapproaches for cancer immunotherapy. Adv Sci (Weinh). 2019;6:1801847.

72. Lou J, Zhang L, Zheng G. Advancing cancer immunotherapies with nanotechnology. Advanced Therapeutics. 2019;2:1800128.

73. Riley RS, June CH, Langer R, Mitchell MJ. Delivery technologies for cancer immunotherapy. Nat Rev Drug Discov. 2019;18:175-96. 
74. Xiao Y, Shi K, Qu Y, Chu B, Qian Z. Engineering nanoparticles for targeted delivery of nucleic acid therapeutics in tumor. Mol Ther Methods Clin Dev. 2018;12:1-18.

75. Uludag $\mathrm{H}$, Ubeda $\mathrm{A}$, Ansari A. At the intersection of biomaterials and gene therapy: progress in non-viral delivery of nucleic acids. Front Bioeng Biotechnol. 2019;7:131.

76. Yu HJ, De Geest BG. Nanomedicine and cancer immunotherapy. Acta Pharmacol Sin. 2020;41:879-80.

77. Sun B, Hyun H, Li LT, Wang AZ. Harnessing nanomedicine to overcome the immunosuppressive tumor microenvironment. Acta Pharmacol Sin. 2020;4:970-85.

78. Huang Y, Fan CQ, Dong H, Wang SM, Yang XC, Yang SM. Current applications and future prospects of nanomaterials in tumor therapy. Int J Nanomedicine. 2017;12:1815-25.

79. Yan S, Zhao P, Yu T, Gu N. Current applications and future prospects of nanotechnology in cancer immunotherapy. Cancer Biol Med. 2019;16:486-97.

80. Shen L, Li J, Liu Q, Song W, Zhang X, Tiruthani K, et al. Local blockade of interleukin 10 and CXC motif chemokine ligand 12 with nano-delivery promotes antitumor response in murine cancers. ACS Nano. 2018;12:9830-41.

81. Curnis F, Fiocchi M, Sacchi A, Gori A, Gasparri A, Corti A. NGR-tagged nano-gold: a new CD13-selective carrier for cytokine delivery to tumors. Nano Res. 2016;9:1393-408.

82. Wang Y, Lin YX, Qiao SL, An HW, Ma Y, Qiao ZY, et al. Polymeric nanoparticles promote macrophage reversal from M2 to M1 phenotypes in the tumor microenvironment. Biomaterials. 2017;112:153-63.

83. Li J, Lin W, Chen $\mathrm{H}, \mathrm{Xu} \mathrm{Z}$, Ye Y, Chen M. Dual-target IL-12-containing nanoparticles enhance $\mathrm{T}$ cell functions for cancer immunotherapy. Cell Immunol. 2020;349:104042.

84. Barbari C, Fontaine T, Parajuli P, Lamichhane N, Jakubski S, Lamichhane P, et al. Immunotherapies and combination strategies for immuno-oncology. Int J Mol Sci. 2020;21:5009.

85. Wei J, Long Y, Guo R, Liu X, Tang X, Rao J, et al. Multifunctional polymeric micelle-based chemo-immunotherapy with immune checkpoint blockade for efficient treatment of orthotopic and metastatic breast cancer. Acta Pharm Sin B. 2019;9:819-31.

86. Wang R, He Z, Cai P, Zhao Y, Gao L, Yang W, et al. Surface-functionalized modified copper sulfide nanoparticles enhance checkpoint blockade tumor immunotherapy by photothermal therapy and antigen capturing. ACS Appl Mater Interfaces. 2019;11:13964-72.

87. Duan X, Chan C, Guo N, Han W, Weichselbaum RR, Lin W. Photodynamic therapy mediated by nontoxic core-shell nanoparticles synergizes with immune checkpoint blockade to elicit antitumor immunity and antimetastatic effect on breast cancer. J Am Chem Soc. 2016;138:16686-95.

88. Wang $\mathrm{C}, \mathrm{Xu} \mathrm{L}$, Liang $\mathrm{C}$, Xiang J, Peng R, Liu Z. Immunological responses triggered by photothermal therapy with carbon nanotubes in combination with anti-CTLA-4 therapy to inhibit cancer metastasis. Adv Mater. 2014;26:8154-62.

89. Mi Y, Smith CC, Yang F, Qi Y, Roche KC, Serody JS, et al. A dual immunotherapy nanoparticle improves T-cell activation and cancer immunotherapy. Adv Mater. 2018;30:e1706098.

90. Wang C, Ye Y, Hochu GM, Sadeghifar H, Gu Z. Enhanced cancer immunotherapy by microneedle patch-assisted delivery of anti-PD1 antibody. Nano Lett. 2016;16:2334-40.

91. Balakrishnan PB, Sweeney EE. Nanoparticles for enhanced adoptive $\mathrm{T}$ cell therapies and future perspectives for CNS tumors. Front Immunol. 2021;12:600659.

92. Stoiber S, Cadilha BL, Benmebarek MR, Lesch S, Endres S, Kobold S. Limitations in the design of chimeric antigen receptors for cancer therapy. Cells. 2019;8:472.

93. Zheng Y, Stephan MT, Gai SA, Abraham W, Shearer A, Irvine DJ. In vivo targeting of adoptively transferred T-cells with antibody- and cytokine-conjugated liposomes. J Control Release. 2013;172:426-35. 
94. Smith TT, Stephan SB, Moffett HF, McKnight LE, Ji W, Reiman D, et al. In situ programming of leukaemia-specific T cells using synthetic DNA nanocarriers. Nat Nanotechnol. 2017;12:813-20.

95. Fadel TR, Sharp FA, Vudattu N, Ragheb R, Garyu J, Kim D, et al. A carbon nanotube-polymer composite for T-cell therapy. Nat Nanotechnol. 2014;9:639-47.

96. Siriwon N, Kim YJ, Siegler E, Chen X, Rohrs JA, Liu Y, et al. CAR-T cells surface-engineered with drug-encapsulated nanoparticles can ameliorate intratumoral T-cell hypofunction. Cancer Immunol Res. 2018;6:812-24.

97. Chen $\mathrm{Q}, \mathrm{Hu} \mathrm{Q}$, Dukhovlinova E, Chen G, Ahn S, Wang C, et al. Photothermal therapy promotes tumor infiltration and antitumor activity of CAR T cells. Adv Mater. 2019;31:e1900192.

98. Nie W, Wei W, Zuo L, Lv C, Zhang F, Lu GH, et al. Magnetic nanoclusters armed with responsive PD-1 antibody synergistically improved adoptive T-cell therapy for solid tumors. ACS Nano. 2019;13:1469-78.

99. Maeng H, Terabe M, Berzofsky JA. Cancer vaccines: translation from mice to human clinical trials. Curr Opin Immunol. 2018;51:111-22.

100. Irvine DJ, Hanson MC, Rakhra K, Tokatlian T. Synthetic nanoparticles for vaccines and immunotherapy. Chem Rev. 2015;115:11109-46.

101. Fu B, Huang X, Deng J, Gu D, Mei Q Deng M, et al. Application of multifunctional nanomaterials in cancer vaccines. Oncol Rep. 2018;39:893-900.

102. Yu X, Dai Y, Zhao Y, Qi S, Liu L, Lu L, et al. Melittin-lipid nanoparticles target to lymph nodes and elicit a systemic anti-tumor immune response. Nat Commun. 2020;11:1110.

103. Liu M, Wang H, Liu L, Wang B, Sun G. Melittin-MIL-2 fusion protein as a candidate for cancer immunotherapy. J Transl Med. 2016;14:155.

104. Bahreyni A, Mohamud Y, Luo H. Emerging nanomedicines for effective breast cancer immunotherapy. J Nanobiotechnology. 2020;18:180.

105. Nguyen TL, Cha BG, Choi Y, Im J, Kim J. Injectable dual-scale mesoporous silica cancer vaccine enabling efficient delivery of antigen/adjuvant-loaded nanoparticles to dendritic cells recruited in local macroporous scaffold. Biomaterials. 2020;239:119859.

106. Zamani P, Teymouri M, Nikpoor AR, Navashenaq JG, Gholizadeh Z, Darban SA, et al. Nanoliposomal vaccine containing long multi-epitope peptide E75-AE36 pulsed PADRE-induced effective immune response in mice TUBO model of breast cancer. Eur J Cancer. 2020;129:80-96.

107. Masjedi A, Hassannia H, Atyabi F, Rastegari A, Hojjat-Farsangi M, Namdar A, et al. Downregulation of A2AR by siRNA loaded PEG-chitosan-lactate nanoparticles restores the $\mathrm{T}$ cell mediated anti-tumor responses through blockage of PKA/CREB signaling pathway. Int J Biol Macromol. 2019;133:436-45.

108. Jadidi-Niaragh F, Atyabi F, Rastegari A, Kheshtchin N, Arab S, Hassannia H, et al. CD73 specific siRNA loaded chitosan lactate nanoparticles potentiate the antitumor effect of a dendritic cell vaccine in 4T1 breast cancer bearing mice. J Control Release. 2017;246:46-59.

109. Liu X, Feng Z, Wang C, Su Q Song H, Zhang C, et al. Co-localized delivery of nanomedicine and nanovaccine augments the postoperative cancer immunotherapy by amplifying T-cell responses. Biomaterials. 2020;230:119649.

110. García-Fernández C, Saz A, Fornaguera C, Borrós S. Cancer immunotherapies revisited: state of the art of conventional treatments and next-generation nanomedicines. Cancer Gene Ther. 2021;28:935-46.

111. Zaheer U, Hassain NA, Banu S, Mathew S. Oncolytic viruses as nanomedicines against the tumor microenvironment. Biointerface Res Appl Chem. 2021;11:14825-52.

112. Lizotte PH, Wen AM, Sheen MR, Fields J, Rojanasopondist P, Steinmetz NF, et al. In situ vaccination with cowpea mosaic virus nanoparticles suppresses metastatic cancer. Nat Nanotechnol. 2016;11:295-303. 
113. Arab A, Nicastro J, Slavcev R, Razazan A, Barati N, Nikpoor AR, et al. Lambda phage nanoparticles displaying HER2-derived E75 peptide induce effective $\mathrm{E}^{-\mathrm{CD}^{+}} \mathrm{T}$ response. Immunol Res. 2018;66:200-6.

114. Barati N, Razazan A, Nicastro J, Slavcev R, Arab A, Mosaffa F, et al. Immunogenicity and antitumor activity of the superlytic $\lambda F 7$ phage nanoparticles displaying a HER2/neu-derived peptide AE37 in a tumor model of BALB/c mice. Cancer Lett. 2018;424:109-16. 